\title{
ИЗУЧЕНИЕ ОСТАТОЧНОЙ МОЩНОСТИ ЛАЗЕРНОГО ОБЛУЧЕНИЯ КОРНЕВЫХ КАНАЛОВ ЦЕНТРАЛЬНЫХ ВЕРХНИХ РЕЗЦОВ ЧЕЛОВЕКА (IN VIVO)
}

\section{THE STUDY OF THE RESIDUAL POWER OF LASER IRRADIATION OF THE ROOT CANALS OF THE CENTRAL UPPER HUMAN INCISORS (IN VIVO)}

E. Zhulev

A. Rostov

A. Rostov

Summary. In laboratory conditions, the residual power of laser radiation was studied after irradiation of the roots of the central upper incisors of a person before and after filling hot gutta-percha under clinical conditions. The dependence of the influence on the residual power of the location of the laser emitter in the root canal (in the apical, middle and wellhead parts) was studied. A comparative analysis of the effectiveness of laser irradiation of the root canal of two high-intensity diode laser systems of the near infrared spectrum with wavelengths of 810 and $980 \mathrm{Nm}$ is carried out.

Keywords: laser system, residual power, root canal of the tooth.

\section{Актуальность}

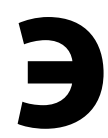

ндодонтическое лечение, является одним из сложных методов лечения в терапевтической стоматологии. Одной из основных проблем в эндодонтической практике остаются сложности топографии корневых каналов, которые приводят к называемым «проблемным каналам» [1, с 186]. Установлено, что очень сложные типы строения корневых каналов не позволяют в полной мере очистить и качественно обработать всю поверхность стенок корневого канала. При формировании каналов некоторые участки остаются недообработанными, что негативно влияет на качество эндодонтического лечения. Также было установлено, что почти 50\% поверхности стенок дентина корневого канала может оставаться вне контакта с эндодонтическими инструментами. Наличие в системе корневого канала боковых ответвления и ответвлений апикальной дельты, которые находятся в концевых трех миллиметрах корня, а также у моляров еще и дополнительных
Жулев Евгений Николаевич

Д.м.н., профессор, ФГБОУ ВО «Приволжский исследовательский медицинский университет» Министерства здравоохранения Российской Федерации hrustalev54@mail.ru

Ростов Андрей Витальевич

К.м.н., главный врач, ООО «Центр медико-правового консультирования «Рубикон»

a_rostov@mail.ru

Ростов Артём Андреевич

Генеральный директор, ООО «Центр медикоправового консультирования «Рубикон» ar-rostov@yandex.ru

Аннотация. В лабораторных условиях изучена остаточная мощность лазерного излучения после облучения корней центральных верхних резцов человека до и после пломбировки горячей гуттаперчей в клинических условиях. Изучена зависимость влияния на остаточную мощность места расположения лазерного излучателя в корневом канале (в апикальной, срединной и устьевой части). Проведён сравнительный анализ эффективности лазерного облучения корневого канала двух высокоинтенсивных диодных лазерных систем ближнего инфракрасного спектра с длинами волн 810 и $980 \mathrm{Hм}$.

Ключевые слова: лазерная система, остаточная мощность, корневой канал зуба.

канальцев в области бифуркации ставит под сомнение возможность тщательного удаления тканей пульпы.

Другой важной проблемой является наличие микроорганизмов в корневой системе. Микроорганизмы, вызывающие эндодонтические заболевания и на $90 \%$ состоящие из облигатных анаэробов, инфицируют не только мягкие ткани пульпы, но и пристеночный предентин корневого канала на глубину до 1,2мм. По данным статистики основной причиной неэффективности эндодонтического лечения является недостаточное уничтожение бактерий в системе корневых каналов - 76\%, неправильное определение показаний к лечению - $22 \%$, отказ от проведения рентгенографии также является одной из причин неэффективности эндодонтического лечения. Удаление патогенной микрофлоры из эндодонта - это этиологический вектор, который определяет клинический курс лечения болезни и плана обработки. Дезинфекция корневого канала крайне важна для регенерации перирадикулярных тканей. 
Несмотря на то, что современная стоматология добилась высоких результатов в лечении зубов после первичной и вторичной эндодонтии, одной из её составляющих является стерилизация корневых каналов, а поиск эффективных методик для уменьшения осложнений и сроков реабилитации является по-прежнему актуальным [2, с. 162-164].

\section{Цель исслеАования}

Изучить остаточную мощность лазерного излучения с различными длинами волн в области корня центральных верхних резцов человека до и после пломбирования каналов горячей гуттаперчей с расположением лазерного излучателя в различных участках корневого канала.

\section{Материалы и методы}

В качестве материала исследования были использованы каналы центральных верхних резцов (зубы 1.1; 1.2) человека. В исследовании использовали две итальянские высокоинтенсивные диодные лазерные системы «Doctor Smile» с длинами волн 810 и 980 Нм. Для измерения дозы лазерного излучения применяли аппарат израильского производства фирмы OPHIR (Laser Measurement Group) PULSAR4 с круглым фотодиодным сенсором (PD300R-UV filter off.) и программным обеспечением - StarLab - (pulsar sensor 3 photodiode PD300RUV (s/n 782471) FU1.27 (s/n 746231).

Параметры лазерного излучения с длинами волн 810 и 980 НМ в лабораторных исследованиях всегда были одинаковыми: мощность 1 Вт; постоянный режим (CW); неактивное оптоволокно толщиной 320 микрон; методика внутриканальная бесконтактная, стабильная; облучение лазером в течение 15 секунд.

\section{Полученные результаты}

Длина канала зуба 1.2 составила 14 мм. Длина канала зуба 1.1 составила 14,7 мм. Каналы зубов были расширены до 35 размера по ISO с шестой конусностью. Диаметр корня резца 1.2 человека на 1 мм выше апекса - 2,3 мм, диаметр середины корня - 3,4 мм, диаметр в области устья - 4 мм. Диаметр корня резца 1.1 человека на 1 мм выше апекса - 2 мм, диаметр середины корня - 4,4 мм, диаметр в области устья - 5,5 мм.

При облучении лазером с длиной волны 810 Нм канала зуба 1.2 до обтурации канала с размещением лазерного излучателя (неактивированного оптоволокна) в корневом канале на 1 мм от апекса, и с расположением круглого фотодиодного сенсора с нёбной поверхности альвеолярного отростка в области проекции корня зуба
1.2. Остаточная мощность за пределами корня составила - 2 мВт, а с длиной волны 980 Нм - 1,1 мВт.

При облучении лазером с длиной волны 810 Нм канала зуба 1.2 до обтурации канала с размещением лазерного излучателя (неактивированного оптоволокна) в корневом канале в области устья, и с расположением круглого фотодиодного сенсора с нёбной поверхности альвеолярного отростка в области проекции корня зуба 1.2. Остаточная мощность за пределами корня составила - 2,25 мВт, а с длиной волны 980 Нм - 1,05 мВт.

При облучении лазером с длиной волны 810 Нм канала зуба 1.2 после обтурации нижней трети канала горячей гуттаперчей с размещением лазерного излучателя (неактивированного оптоволокна) в корневом канале в области устья, и с расположением круглого фотодиодного сенсора с нёбной поверхности альвеолярного отростка в области проекции корня зуба 1.2. Остаточная мощность за пределами корня составила $-2,25$ мВт, и с длиной волны $980 \mathrm{HM}-2,25$ мВт.

При облучении лазером с длиной волны 810 Нм канала зуба 1.1 до обтурации канала с размещением лазерного излучателя (неактивированного оптоволокна) в корневом канале на 1 мм от апекса, и с расположением круглого фотодиодного сенсора с нёбной поверхности альвеолярного отростка в области проекции корня зуба 1.2. Остаточная мощность за пределами корня составила - 8,5 мВт, а с длиной волны $980 \mathrm{Hм}-3,19$ мВт.

При облучении лазером с длиной волны 810 Нм канала зуба 1.1 до обтурации канала с размещением лазерного излучателя (неактивированного оптоволокна) в корневом канале в области устья, и с расположением круглого фотодиодного сенсора с нёбной поверхности альвеолярного отростка в области проекции корня зуба 1.1. Остаточная мощность за пределами корня составила - 9,1 мВт, а с длиной волны 980 Нм - 6 мВт.

При облучении лазером с длиной волны 810 Нм канала зуба 1.1 после обтурации нижней трети канала горячей гуттаперчей с размещением лазерного излучателя (неактивированного оптоволокна) в корневом канале в области устья, и с расположением круглого фотодиодного сенсора с нёбной поверхности альвеолярного отростка в области проекции корня зуба 1.1. Остаточная мощность за пределами корня составила -7 мВт, и с длиной волны $980 \mathrm{Hм}-4,8$ мВт.

\section{Обсужление \\ полученных результатов}

Из полученных результатов видно, что при облучении лазером корневых каналов как с длиной волны 810 
Нм, так и с длиной волны 980 Нм лазерная энергия полностью не поглощается твёрдыми тканями корней зубов $1.1 ; 1.2$ и альвеолярного отростка, как до, так и после обтурации канала, а проходит наружу. Даже при расположении лазерного излучателя на 1 мм от апекса и при расположении его в области устья в канале зубов 1.1; 1.2, часть лазерной энергии проходит через все твёрдые ткани корня и альвеолярный отросток и выходит наружу. В исследованиях видно, ткани человека почти в 2 раза больше поглощают лазерную энергию с длиной волны 980 Нм. Остаточная мощность лазерной энергии с длиной волны 810 Нм больше выходит за границы корней зубов 1.1; 1.2. Лазерная энергия выходит за пределы корня и альвеолярного отростка даже после частичной обтурации корневых каналов в нижней трети горячей гуттаперчей зубов 1.1; 1.2 .

\section{Зак^ючение}

Проведенное исследование позволяет сделать вывод о том, что лазерная энергия с длинами волн 810 и $980 \mathrm{Hм}$ не только поглощается хромофорами тканей корня зуба и альвеолярного отростка, но и проникает их насквозь, выходя за пределы всех тканей человека вне зависимости от расположения лазерного излучателя в различных участках корневого канала.

Лабораторный эксперимент показал, что на остаточную мощность лазерного излучения, прошедшую через твёрдые ткани корня, при обработке корневых каналов в большей степени влияет длина волны лазера, и в меньшей степени место расположения излучателя в корневом канале зуба. Даже частичная обтурация корневых каналов зубов 1.1; 1.2 мало влияет на остаточную мощность лазерного излучения.

На основании полученных результатов (in vivo) также можно сделать вывод о том, что лазерное излучение с длиной волны 980 Нм эффективнее для стерилизации корневых каналов в первичной эндодонтии, чем с длиной волны 810 Нм. Однако, по нашему мнению, лазер с длиной волны 810 Нм предпочтительнее использовать во вторичной (повторной) эндодонтии с периапикальными осложнениями.

\section{ЛИТЕРАТУРА}

1. Н.Т. Байназарова, М. К. Искакова «Анализ качества эндодонтического лечения, профилактика осложнений (по данным литературы), вестник КазНМУ № 3-2017, с 186.

2. Жулёв Е.Н., Ростов А. В., Ростов А. А. Изучение остаточной мощности после лазерного облучения корневых каналов удалённого моляра человека // Современная наука: актуальные проблемы теории и практики. Серия «Естественные и технические науки» -№ 8,_-2019 г.,- С. 162-164. 